\title{
HOCHWERTIGE LICHTSCHALTER FÜRS MENSCHLICHE GEHIRN
}

\section{Liebe Kolleginnen und Kollegen,}

wenn viele belastende Fakten wie Pandemie oder Terroranschläge passieren und viele das Gefühl haben, dass alles so schrecklich ist, ist es besonders wichtig, auch über Positives zu berichten. Die Photobiomodulation (PBM) ist eine bereits etablierte Methode zur Stimulierung der mitochondrialen Aktivität mit Licht. Derzeit arbeiten zahlreiche Forscher ${ }^{\star}$ innen daran, die PBM zu verwenden, um die Gehirnaktivität zu modifizieren, in der Hoffnung, klinisch wertvolle Instrumente zur Bekämpfung neurologischer Defizite zu entwickeln. Neben wichtigen Tierversuchen stellt dabei gerade die Quantifizierung derWirkung von PBM auf die Aktivität des menschlichen Gehirns eine Herausforderung dar. An der Medizinischen Universität Graz untersuchten wir u.a. die Auswirkungen eines Photobiomodulationshelms. Analysiert wurden beispielsweise die regionale zerebrale Sauerstoffsättigung und komplexe Parameter von Hirnstrommessungen. Wir konnten zeigen, dass die Sauerstoffversorgung des Blutes während der PBM anstieg und nach der PBM abfiel, jedoch auf ein höheres Niveau als der Ausgangszustand. Obwohl wir von den messbaren Effekten überzeugt sind, erkennen wir an, dass noch viele Fragen offen sind. Parameter wie Leistungsdichte, Belichtungsdauer, Lichtfrequenz und viele mehr sind alle noch näher zu untersuchen. Wir müssen dazu grundlegende Experimente durchführen, um die klinische Verwendung des Helms zu beschleunigen. Erste richtungsweisende Ergebnisse sind nun in einem soeben erschienen Band mit dem Titel „Transcranial Photobiomodulation“ (Ed. Gerhard Litscher, 2021, 216 Seiten) in englischer Sprache erschienen. In Ergänzung dazu wurde während der Pandemiekrise auch das erste Textbuch über Laserakupunktur und Lasermedizin in Chinesischer Sprache veröffentlicht (Abb. 1).

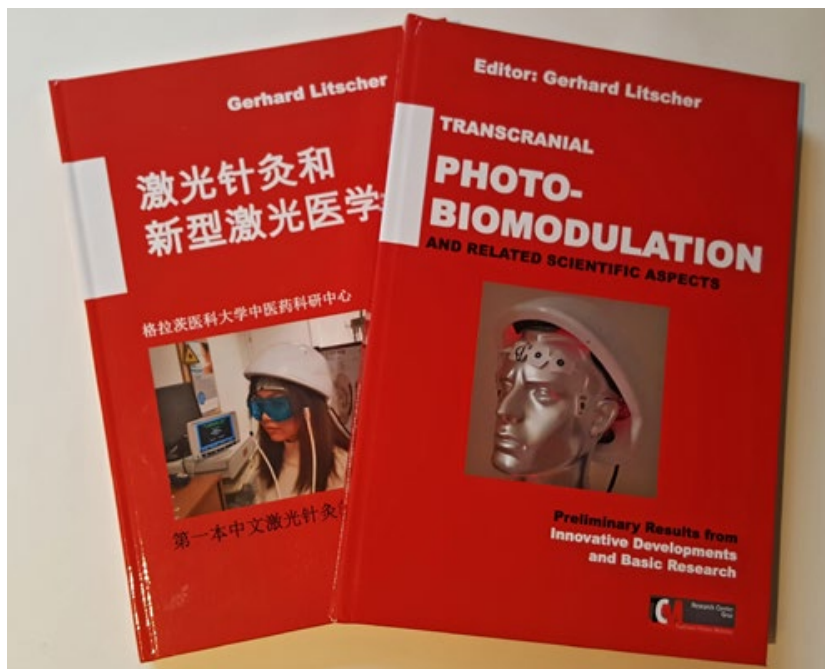

Abb. 1: Zwei weitere Buchbände, die während der COVID-19-Pandemie 2020/2021 am TCM Forschungszentrum in Graz publiziert wurden (Foto (C) G. Litscher)

Mit Veröffentlichungen, wie beispielsweise jener in unserer Zeitschrift Akupunktur und Aurikulomedizin kann nicht nur fachspezifische, wichtige Information transportiert werden, diese können auch Lebensfreude reaktivieren. Man kann beim Lesen für eine Weile das Stressende vergessen und in die motivierende und hoffentlich heilende Welt der Akupunktur und Aurikulomedizin versinken.

Allen Leserinnen und Lesern dieser Ausgabe wünschen wir trotz in vielen Fällen notwendiger Distanz ein gesegnetes und gesundes Weihnachtsfest.
Univ.-Prof. Prof. h.c. DI Dr. techn.

Dr. scient. med. Gerhard Litscher

President for Science and Research der International Society for Medical Laser Applications (ISLAtranscontinental) Medizinische Universität Graz, Auenbruggerplatz 39, EG19, A-8036 Graz, Tel: +43 316/385-83907 E-Mail:gerhard.litscher@medunigraz.at 